\title{
Diagnosis of Vascular Dementia: Consortium of Canadian Centres for Clinical Cognitive Research Concensus Statement
}

\author{
Kenneth Rockwood, Irma Parhad, Vladimir Hachinski, Timo Erkinjuntti, \\ Barry Rewcastle, Andrew Kertesz, M. Robin Eastwood and Stephen Phillips
}

\begin{abstract}
Interest in vascular causes for cognitive impairment is increasing, in recognition that such causes are common, and possibly preventable. This has led to attempts to better define vascular dementia and its natural history. Several sets of criteria for the diagnosis of vascular dementia have been proposed. We provide a brief overview of the background to the initiation of a Canadian consensus conference, established by the Consortium of Canadian Centres for Clinical Cognitive Research (C5R) and report the conclusions reached at that conference. To date, no one set of criteria is demonstrably superior to another; we have therefore not endorsed any of the competing sets, nor have we recommended our own. Instead we suggest that empiric studies are required to establish valid criteria. A diagnostic checklist, which combines existing criteria and additional data, is attached for clinicians wishing to participate in such studies.
\end{abstract}

\begin{abstract}
Résumé: Diagnostic de la démence vasculaire: consensus du consortium des centres canadiens pour recherche clinique sur la cognition. L'intérêt pour les causes vasculaires des déficits cognitifs a augmenté depı que l'on sait que ces causes sont fréquentes et qu'on peut possiblement les prévenir. De là les efforts pour miet définir la démence vasculaire et décrire son évolution naturelle. Plusieurs séries de critères pour le diagnostic de démence vasculaire ont été proposées. Nous faisons un bref rappel du contexte dans lequel la conférence pour u consensus canadien, établie par le Consortium des centres canadiens pour la recherche clinique sur la cognition, : été amorcée et nous en rapportons les conclusions. Aucun ensemble de critères ne s'est avéré supérieur aux autre: jusqu'à maintenant; nous n'en avons donc recommandé aucun, même pas le nôtre. Nous croyons que des études empiriques sont nécessaires pour établir des critères valides. Nous présentons une grille diagnostique incluant des critères actuels et des données additionelles à l'intention des cliniciens qui désirent participer à ces études.
\end{abstract}

Can. J. Neurol. Sci. 1994; $21:$ 358-364

The considerable current and future burden posed to society by dementing illnesses is often underappreciated. It has been estimated that the cost of caring for those with dementia (acquired, global, progressive cognitive impairment) exceeds the combined costs of heart disease and cancer.' In consequence, the study of dementia is receiving increased attention. With this increased attention has come an increased recognition of vascular causes of dementia, and the important potential for prevention. Much controversy about vascular dementia exists, however. ${ }^{2-5}$ This is in part due to persisting controversy about the definition of the syndrome, the relationship between vascular brain injury and dementia, ${ }^{2}$ and the difficulty in distinguishing vascular dementia from Alzheimer's disease in life. ${ }^{6-10}$

Two recent proposals for changes in the diagnostic criteria for vascular dementia lay the groundwork by which some of these controversies might be addressed. ${ }^{11.12}$ Although the validity of neither set of criteria has been established in any published study, ${ }^{13}$ the criteria potentially have fundamental implications for our understanding of the epidemiology, mechanisms and potential prevention and treatment of vascular dementia.

\section{The Consensus Conference}

To determine how Canadian investigators might diagnose vascular dementia, a consensus conference was held on June 15 , 1993 in Toronto, in conjunction with the Canadian Neurological Sciences Congress. The conference was organized under the auspices of the Consortium of Canadian Centres for Clinical

\footnotetext{
From the Consortium of Canadian Centres for Clinical Cognitive Research. RECEIVED ARPIL 11, 1994. ACCEPTED IN FINAL FORM JUNE 11, 1994. Reprint requests to: Kenneth Rockwood, Division of Geriatric Medicine, Dalhousie University, 1763 Robie Street, Halifax, Nova Scotia, Canada B3H 3G2
} 
Cognitive Research (C5R) which was formed in 1992 by a group of investigators interested in collaborative work on dementia. All members of the C5R were invited to attend the conference, and the conference was publicised through the CCNS conference advertising, and to members of the Canadian Study of Health and Aging network. The conference was open to any interested investigator. The conference was attended by approximately 70 people, and included neurologists, geriatricians, neuropsychologists and epidemiologists.

At the conference, small group discussions were led by each of the co-authors, who also made invited contributions. From this, a consensus statement was proposed at the meeting. Subsequent modifications of the statement were made in successive rounds of discussions and mailings, some of which also included comments from the members of the C5R executive. The authorship of the document remained unchanged after its inception.

\section{BACKGROUND}

\section{Historical overview}

Several commentators have noted the resurgence of the concept of vascular dementia. ${ }^{15-17}$ Early thinking about dementia viewed the cause as "hardening of the arteries", giving rise to chronic hypoperfusion. With the rise of interest in Alzheimer's disease, the notion of vascular dementia was gradually supplanted. For a time the standard thinking was that, in Western countries, (estimates from Japan and the East have always been higher ${ }^{18}$ ) "multi-infarct dementia", as it was usually called, accounted for no more than $15 \%$ of dementia cases, and even that figure was thought by some to be an overestimate. ${ }^{6}$ Multi-infarct dementia, a term coined before the widespread use of CT scans and defined as dementia arising as a consequence of multiple strokes, was often incorrectly used as a synonym for vascular dementia, "overshadowing the search for other possible causes". ${ }^{2}$ With a broadening of the concept of vascular dementia, and with the advent of better and more accessible neuroimaging, some now argue that, alone or in combination with Alzheimer's disease, a vascular cause is present in up to $50 \%$ of Western cases of dementia. ${ }^{16}$

The true frequency of vascular dementia remains unknown. This is a consequence of both the problem of definition and the lack of unbiased (i.e. population-based) studies. For example, while Tatemichi et al. state that, from autopsy series, cerebral infarction accounts for up to $25 \%$ of all dementias ${ }^{19}$ - with another $15 \%$ mixed $\mathrm{AD}$ and vascular - clinical studies reveal only $15 \% .{ }^{17}$

Interest in better defining vascular dementia - and thus determining its frequency - increases, and is driven by the potential for prevention. Hachinski's "call for action against the vascular dementias"3 has thus received widespread support. In this context, new vascular dementia criteria have been developed. ${ }^{11,12}$

\section{Current Concepts and Controversies}

While it is readily appreciated that multiple strokes can give rise to acquired, global cognitive impairment, there is dispute about how to classify dementia arising from well-known stroke syndromes, from single strategic strokes, from small vessel disease and white matter changes, from hypoperfusion or from other non-stroke cardiovascular causes. Fundamental questions also remain about the mechanisms of vascular dementia.
Diagnostic criteria arising from a view of dementia dominated by the dementia syndrome of Alzheimer's disease may not reflect dementia syndromes arising as a consequence of vascular causes. ${ }^{2,4}$ Indeed, Erkinjuntti and Hachinski have argued that "dementia as an identifier could well be abandoned, and the focus should be early changes in a person's cognitive abilities, personality and mood, which may be signalling the prelude to early vascular dementia." 2 This is a fundamental question in the elucidation of the vascular dementia syndrome, not least because some investigators, including conference participants, believe that it is inappropriate to include cognitive impairment short of dementia in the definition of this syndrome.

The notion that chronic cerebral ischemia may give rise to dementia without causing frank infarction has generated much controversy. Although chronic hypoperfusion is known to give rise to kidney failure and/or to heart failure in the absence of frank infarction, ${ }^{21.22}$ there has been reluctance to accept this as a possible mechanism of vascular dementia, ${ }^{11,12}$ as it too strongly harkens back to the old "hardening of the arteries" concept. . $^{2.10}$ Indeed, Tatemichi has explicitly stated that there should be little vascular dementia arising which cannot be explained by the focal effects of cerebral infarcts. ${ }^{10}$ Similarly, Marshall in a review of cerebral blood flow studies in vascular dementia states that "reduction in $\mathrm{CBF}$ [cerebral blood flow] does not cause vascular dementia". ${ }^{20}$ On the other hand Brun and Englund ${ }^{23}$ observed histopathologic changes in the cerebral white matter of demented patients, which they attributed to "incomplete infarction". It has been suggested that such changes may result from chronic ischemia caused by arteriolosclerosis ${ }^{24}$ or amyloid angiopathy ${ }^{25}$ of the long perforating arteries to the white matter. In addition, Vinters and Mah, in consideration of the nonischemic pathologic changes seen in the cerebral cortex of patients with cerebral amyloid angiopathy (with and without Alzheimer's disease) speculate that vascular dementia may occur via currently unknown mechanisms that need not include frank infarction. ${ }^{26}$

\section{Diagnostic criteria}

Several sets of diagnostic criteria for vascular dementia exist, namely: the Hachinski Ischemic Score, ${ }^{27}$ and its modified version; ${ }^{28}$ the ICD-9 definition of arteriosclerotic dementia; ${ }^{29}$ the ICD-10 definition of vascular dementia; ${ }^{30}$ the DSM-III and DSM-III-R definitions of multi-infarct dementia; ${ }^{31.32}$ the CAMDEX definition of multi-infarct/vascular dementia; ${ }^{33}$ and the vascular dementia criteria of Erkinjuntti. ${ }^{34.35}$ These criteria contain variable mixes of clinical, neuropsychologic and radiographic characteristics. The most recent criteria are those proposed by the California Alzheimer Treatment Centres, " and jointly by an American/European consensus group (NINDS/AIREN). ${ }^{12}$ We will next focus on these two.

Both the California and NINDS-ARIEN criteria are conceptually similar but differ in several details. The basic requirements for a diagnosis of vascular dementia are: a) the presence of dementia; b) evidence of vascular brain lesions; and c) an appropriate temporal relationship between the two. The California criteria include a newly stated definition of dementia, whereas the NINDS-AIREN criteria define dementia according to the 10th revision of the Neurological Adaptation of the International Classification of Diseases (ICD-10NA) ${ }^{30}$ Both sets of criteria indicate the importance of neuropsychological 
assessment in the diagnosis of dementia but point out that the ideal battery of tests has not yet been developed and validated.

The criteria differ in the types of vascular brain lesions which they include. The California criteria exclude haemorrhagic lesions whereas the NINDS-AIREN criteria include them. The NINDS-AIREN criteria also recognize dementia arising from cardiac causes as vascular dementia; the California criteria do not.

Both sets of criteria require a brain imaging study (either CT or MR) to define the presence of vascular brain lesions. Although in either set a solitary infarct is sufficient, provided that its occurrence immediately precedes the onset of dementia, neither recognizes vascular dementia arising from chronic hypertension without radiographic evidence of ischemic damage. Diffuse white-matter changes on CT or MR scans are not a requirement for diagnosis, though their presence is considered supportive.

Both sets of criteria define definite, probable, and possible cases, and specify features that cast doubt on the diagnosis of vascular dementia. The California criteria specify that a diagnosis of "mixed dementia" be made in the presence of one or more systemic or brain disorders that are thought to be causally related to the dementia. The NINDS-AIREN criteria avoid using "mixed dementia" and instead use "Alzheimer's disease with cerebrovascular disease" to classify patients who fulfill the clinical criteria for possible Alzheimer's disease and who also present clinical or imaging evidence of relevant vascular brain lesions. The NINDS-AIREN criteria include dementias arising as a consequence of hypoperfusion from cardiac dysrythmias and pump failure, but the California criteria do not.

Both sets of criteria have been criticized. Drachman, in an editorial accompanying the NINDS-AIREN criteria, noted that there is likely to be persisting argument over which cases to include, how to ascribe causality to the lesions seen, how to interpret the neuroimaging studies, and how to view the effects of ischemia on brain function in the absence of strokes. ${ }^{13} \mathrm{He}$ suggested a few remedies, including the introduction of the notion of "primary" and "secondary" vascular dementia. He found it particularly striking that the NINDS-AIREN criteria would include all stroke patients with subsequent intellectual loss and suggested that the term "stroke with secondary dementia" be used when the dementia is associated with a recognized stroke syndrome, and "primary vascular dementia" when there is no recognized stroke syndrome. There is also concern that the focus on dementia will mean that patients with mild cognitive impairment short of dementia (who could stand to benefit most from intervention) will not receive sufficient attention. ${ }^{1}$

\section{Neuropsychology of vascular dementia}

Patients with vascular brain injury display a variety of patterns of impairment on neuropsychologic tests, as might be expected given that the vascular lesions may affect different parts of the brain. Attempts to categorize neuropsychologic patterns of impairment have had incomplete success, ${ }^{35.36}$ and remain controversial. In general, patients who have well circumscribed deficits explicable on the basis of cerebral infarcts demonstrated by CT or MR usually do not pose diagnostic problems. ${ }^{25}$ Multiple, small subcortical infarcts which typically involve the white matter around the anterior horns of the lateral ventricles, the head of the caudate nucleus, and the putamen, can produce neuropsychological signs of frontal lobe dysfunction even in the absence of clinically detectable dementia. ${ }^{37.38}$ How these findings should be translated into routine tests for clinical practice remains unclear. In addition, it is important to note that some cerebral infarcts are, by current test standards, both neuropsychologically and clinically silent. ${ }^{20.39}$

More controversial are the neuropsychologic correlates of diffuse white matter changes seen on brain imaging studies. Some investigators have found that the changes are associated with cognitive impairment, ${ }^{40-42}$ while others have not. ${ }^{43-46}$ Such discrepancies are probably explicable on the basis of selection bias, different definitions of cognitive impairment, interobserver variation in the definition of the white matter changes, and the heterogeneity of the underlying histopathologic changes.

Vascular dementia is a syndrome and not a single disease entity. Whether there exists a pattern of cognitive deficits, detectable by neuropsychologic testing, that can be considered characteristic of this syndrome remains an important question.

\section{Neuroimaging of vascular dementia}

CT and MR are the radiographic techniques most often used in studies of vascular dementia. Interest has focused on two types of lesion: infarcts and white matter changes. MR is more sensitive for the detection of small infarcts than CT. Brown et al. ${ }^{47}$ found that CT detected $64 \%$ of the small deep infarcts that were detected by $\mathrm{MR}$ in patients examined retrospectively. Larger infarcts, however, are detected well by both CT and MR. Patients with dementia more often have supratentorial cortical infarcts than small deep ones. ${ }^{48}$

The interpretation of neuroradiographically-imaged white matter changes in the brain has been a source of persisting controversy. In 1987, Hachinski et al. proposed the term "leukoaraiosis" to describe the white matter rarefaction seen on CT scans, but noted that this did not imply an associated cognitive deficit, or a mechanism of causation. ${ }^{49}$ In consequence, it is possible to define separately the clinical, radiographic and pathological findings. As noted above however, the neuropsychologic correlates of white matter changes are unclear, both for patients with dementia and for apparently healthy volunteers.

$\mathrm{MR}$ is more sensitive than $\mathrm{CT}$ in detecting periventricular and other white matter abnormalities. For example, Kobari et al. ${ }^{50}$ showed that $68 \%$ of 31 normal and demented patients had abnormally high periventricular signal on MRI, but only $45 \%$ of these patients had leuko-araiosis on CT. Of 6 neurologically normal elderly volunteers, 5 had periventricular signal abnormalities on MRI, but no leukoaraiosis on CT. On the other hand, this sensitivity is offset by low specificity; white matter abnormalities demonstrated by MR are due to a variety of histopathological changes, e.g., swollen myelin sheaths, loss of myelin and oligodendroglia with relative preservation of axons, cystic change resulting from destruction of both axons and myelin, edema, subependymal glial accumulations, and dilated perivascular (Virchow-Robin) spaces (etat crible). ${ }^{51,52}$

CT is nevertheless reasonably sensitive to white matter changes in the brain. ${ }^{53.54}$ Inzitari et al. ${ }^{55}$ detected leuko-araiosis by $\mathrm{CT}$ in $49 / 140(35 \%)$ demented patients, compared with $12 / 110(11 \%)$ control subjects, and found that a history of stroke was four times more frequent in patients with leuko-araiosis than in those without. In another study of 275 normal and demented subjects aged 23-85 years, George et al. ${ }^{56}$ found that 
white matter lucencies on CT were more common in demented patients than in normal subjects, but the difference was not statistically significant, and that the severity of the changes was not related to the degree of dementia.

Through the widespread use of brain imaging in clinical medicine, it has become clear that not all cerebral infarcts are associated with a recognized stroke illness. This situation is analogous to that of silent myocardial infarction in which diagnostic electrocardiographic abnormalities are found in a patient who has not experienced any cardiac symptoms. The occurrence of silent cerebral infarction has the potential to result in underdiagnosis of vascular dementia if such a diagnosis is dependent on a history of a stroke. Conversely, if a silent cerebral infarct is an "incidental" finding in a patient who, in fact, has Alzheimer's disease, over-reliance on brain imaging studies will tend to result in over-diagnosis of vascular dementia. The frequency of silent cerebral infarction in the general population is unknown. Data from the Framingham Study ${ }^{57}$ and the Stroke Data Bank ${ }^{58}$ indicate that about $10 \%$ of patients who come to medical attention because of ischemic stroke have CT scan evidence of a previous asymptomatic cerebral infarct.

The potential effect of neuroimaging on reclassification can be estimated from a recent report from Sweden. ${ }^{59}$ Skoog et al. investigated prevalence and causes of dementia in 494 people aged 85 and older. Prior to having the CT scan report, clinicians diagnosed Alzheimer's disease in 46 cases, vascular dementia (using the Erkinjuntti ${ }^{8}$ criteria) in 42 cases, and other dementias in 11 subjects. After the CT scan report was known, these diagnoses were changed in 10 cases $(10 \%)$, so that 37 cases were said to have Alzheimer's disease, 57 had vascular dementia, and 10 had other dementias.

In brief, technical and economic considerations make it impractical to mandate the use of MRI in the diagnosis of vascular dementia. Furthermore, the logistical and economic implications would be prohibitive. Given the widespread availability of third and fourth generation CT scanners, which produce excellent images, a requirement for neuroimaging in support of a diagnosis of vascular dementia is feasible in this country. Correlation of neuroimaging and cognitive impairment faces a special challenge from supposed "silent" cerebral infarctions, particularly in patients who may have Alzheimer's disease or another cause of dementia. Including neuroimaging data in the operational definition of vascular dementia makes it impossible to evaluate both the contribution of neuroimaging and the question of vascular cognitive impairment in chronic ischemia without frank infarction. Careful clinical follow-up with neuropathologic confirmation will be particularly important in these patients.

\section{Neuropathology of vascular dementia}

Neuropathologic confirmation of clinical changes provides the "gold standard" in most neurologic diagnosis. That this is not the case in vascular dementia is evident from the realisation that vascular dementia is a syndrome, not a disease. While it might nevertheless be hoped that clinical-pathologic correlation between focal infarcts and their clinical effects will result in final confirmation of many cases of vascular dementia, conceptual and technical challenges remain. One such conceptual challenge is that of finding appropriate correlates of vascular cognitive impairment without frank infarction.

From a technical standpoint, infarcts collapse with the age of the infarct, potentially confounding the relationship between infarct volume and effect. In addition, determining the volume of lesions is quite difficult for white matter infarcts.

Despite these obstacles, neuropathologic diagnosis must of course be carried out. The most widely used criterion has been the presence of ischemic brain lesions in the absence of Alzheimer or other diagnostic changes. ${ }^{2}$ Erkinjuntti et al. have reported $90 \%$ accuracy in the clinical diagnosis of vascular dementia, as compared with autopsy. ${ }^{8}$

\section{Summary Consensus Statement:}

1. Given the possibility for prevention of an important source of morbidity, studies of vascular dementia are necessary and important.

2. As there is little empiric study which validates existing criteria, or establishes their widespread generalizeability, no set is demonstrably superior to any other set.

3. Future studies of vascular dementia should therefore incorporate studies of the existing criteria, where possible with neuropathologic confirmation. As the site, frequency and volume of lesions that may cause important cognitive impairment will vary, neuropathologic confirmation requires careful clinical-pathologic correlation.

4. An important area for further study is the very notion of vascular "dementia"; data may show that "vascular cognitive impairment" ${ }^{100}$ is a more apt term, as a focus for prevention.

5. Further studies of criteria for vascular cognitive impairment should include both population-based and clinic-based samples.

6. In the diagnosis of vascular dementia, clinical, neuroradiographic, neuropathologic and neuropsychologic criteria should be investigated and correlated. A multidisciplinary approach is therefore important.

7. The societal need for prevention requires a broad focus; the scientific need for precision requires careful classification. Both needs can likely be met by a broad classification with detailed categories contained therein. The best method of categorization (by cause, by clinical presentation, by radiographic appearance) has yet to be determined.

8. Widespread voluntary use by clinicians seeing patients with vascular neurologic disease of a diagnostic checklist which incorporates both existing criteria and data likely to meet criticisms of these criteria could provide important information on their measurement properties. A sample form is attached, and further information on participation in this study, which will include tests of validity and reliability, can be obtained from any co-author, or from the C5R secretariat.

\section{CONCLUSION}

Given the potential for prevention and treatment of this form of dementia, a precise understanding of its prevalence is desirable. ${ }^{3}$ As there is potential for bias in coming too quickly to conclusions about what is and what is not vascular dementia, we have developed a broadly focused consensus statement. At the same time, we have attempted to meet the scientific need for precision by proposing that specific subtypes of vascular dementia be validated within this broad conceptual framework.

We believe that many of the controversies raised by the competing sets of diagnostic criteria for vascular dementia can be cast as empiric questions, which may then be further investigated. We invite our colleagues to take part in national clinic-based and population studies of these issues. 
APPENDIX. Sample data collection form incorporating existing vascular dementia criteria.

C5R Vascular Dementia Checklist

(Source: 1 = California criterion, 2 = NINCDS-AIREN criterion)

\section{A. DIAGNOSTIC CHECKLIST FOR DEMENTIA 1.2}

$\begin{array}{lllll}\quad 0=\text { Yes } \quad \text { (Circle) } & & & \\ \text { 1. Intellectual impairment } & & 0 & 1 & 2 \\ \text { 2. Acquired } & & 0 & 1 & 2 \\ \text { 3. Progressive } & & 0 & 1 & 2 \\ \text { 4. Interferes with daily functioning } & 0 & 1 & 2 \\ \text { 5. Clear sensorium (i.e. not delirium) } & 0 & 1 & 2 \\ \text { 6. Memory impairment } & 0 & 1 & 2 \\ \text { short term memory impairment } & 0 & 1 & 2 \\ \text { long term memory impairment } & 0 & 1 & 2 \\ \text { memory impairment, most prominent feature 2 only } & 0 & 1 & 2 \\ \text { 7. Aphasia } & 0 & 1 & 2 \\ \text { 8. Apraxia } & 0 & 1 & 2 \\ \text { 9. Agnosia } & 0 & 1 & 2 \\ \text { 10. Impaired concentration } & 0 & 1 & 2 \\ \text { 11. Disorientation } & 0 & 1 & 2 \\ \text { 12. Impaired simple calculation } & 0 & 1 & 2 \\ \text { 13. Psychomotor agitation } & 0 & 1 & 2 \\ \text { 14. Impaired judgment } & 0 & 1 & 2\end{array}$

\section{B. DIAGNOSTIC CHECKLIST FOR VASCULAR ABNORMALITIES}

\section{History}

A. Of stroke (definition: a focal or sometimes global disturbance of cerebral function lasting longer than 24 hours, or resulting in death, of presumed vascular cause) 1.2

1. Number of strokes (record 0 for none)

2. Number of strokes before onset of dementia (if stroke occurred after dementia, code 0 )

3. Months since first stroke (if no stroke, leave blank)

4. Months since stroke which most recently preceded dementia (if none, leave blank; if less than one, code I)

B. Of transient ischemic attacks 1.2

1. Number of TIA's (record 0 for none)

2. Number of strokes before onset of dementia (if stroke occurred after dementia, code 0 )

3. Months since first TIA (if no TIA, leave blank)

4. Months since TIA which most recently preceded dementia (if none, leave blank: if less than one, code I)

C. Of clinical features thought to be associated with vascular dementia:
$0=$ Yes $\quad 1=$ No $\quad 2$ = Inadequate Information

1. Relatively early appearance of gait disturbance (small-step gait: marche a petit pas, magnetic, apraxic-ataxic, or parkinsonian gait) ${ }^{1.2}$

2. Early urinary frequency, urgency and other urinary symptoms not explained by urologic disease, or non-vascular neurologic disease 1.2

3. History of unsteadiness, and frequent unprovoked falls $1.2 \quad$ O 1

4. Pseudobulbar palsy ${ }^{2}$

$\begin{array}{lll}0 & 1 & 2\end{array}$

5. Personality and mood changes, abulia, depression,

$\begin{array}{llll}0 & 1 & 2\end{array}$ emotional incontinence ${ }^{2}$

6. Psychomotor retardation

7. Abnormal executive function 1.2

$0 \begin{array}{lll}0 & 1 & 2\end{array}$

D. Of other possibly associated clinical features: ${ }^{1}$

1. Slowly progressive symptoms

2. Illusions, psychosis, hallucinations, delusions

3. Seizures

0 112

Of vascular risk factors:

1. Hypertension

2. Smoking

3. Diabetes mellitus

4. Hypercholesterolemia

$\begin{array}{lll}0 & 1 & 2\end{array}$

$\begin{array}{lll}0 & 1 & 2\end{array}$

$\begin{array}{lll}0 & 1 & 2\end{array}$

Of vascular comorbidity:

1. Angina/myocardial infarction

2. Atrial fibrillation

3. Sick sinus syndrome, 2 nd or $3 \mathrm{rd}$ degree or bifascicular block or other supraventricular dysrythmias (circle)
4. Cardiac arrest, or other ventricular dysrythmias

5. Congestive heart failure

$\begin{array}{lll}0 & 1 & 2\end{array}$

6. Peripheral vascular disease

G. Of vascular procedures: (circle)
1. Pacemaker implantation
2. Coronary artery bypass graft
within last year
last 5 yrs within last year last $5 \mathrm{yrs}$
longer or open-heart surgery

3. Coronary angioplasty

4. Carotid endarterectomy

within last year last 5 yrs within last year last 5 yrs within last year last 5 yrs

Extracranial-intracranial bypass

6. Intracranial aneurysm/AVM repair

last 5 yrs longer

7. Peripheral vascular surgery

within last

last 5 yrs longer

last 5 yrs longer

II. Physical examination 1.2

$$
0=\text { Yes } \quad 1=\text { No } \quad 2=\text { Inadequate Information }
$$

1. Aphasia

$\begin{array}{lll}0 & 1 & 2\end{array}$

2. Dysarthria

3. Hemianopia

4. Dysphagia

5. Hemimotor dysfunction (excluding cerebellar findings)

6. Hemisensory dysfunction

7. Reflex asymmetry

8. Babinski sign

9. Other focal findings (circle); cerebellar findings

10. Other non-focal findings (circle): parkinsonism, essential tremor, other movement disorder, cerebellar findings

III. Neuropsychologic test findings 1.2
1. Amnesia
2. Aphasia
3. Acalculia
4. Apraxia
5. Agnosia
6. Impaired executive functions
7. Pattern of focal deficits

IV. CT scan findings: 1.2

1. Normal

2. Diffuse cerebral atrophy disproportionate for age

3. Cortical infarct(s) - list number (none $=0$ )

4. Subcortical infarct(s) - list number (none $=0$ )

5. Leukoaraiosis: (circle) absent, periventricular, diffuse

6. Other abnormality: (circle) hydrocephalus; meningioma: other tumor; arachnoid cyst, other

V. Other neurodiagnostic tests: (circle) MRI 1.2 SPECT PET

VI. Stroke type: 1.2

1. cerebral infarct

2. intracerebral hemorrhage

3. subarachnoid hemorrhage

4. unknown

viI. Stroke location 1.2

cortical:

Left frontal

Left temporal

Left parietal

Left occipital

Right frontal

Right temporal

Right parietal

Right occipital

subcortical:

Left internal capsule

Right internal capsule

Left thalamus

Right thalamus

Right basal ganglia

Left basal ganglia

Right cerebellum

other:

Left cerebellum

Brainstem 


\section{ACKNOWLEDGEMENTS}

The authors are grateful to Hoffman LaRoche Canada who provided funding for the consensus conference, held June 15 in Toronto, in conjunction with the Canadian Neurological Sciences Congress. Dr. Erkinjuntti's visit was sponsored by the Royal College of Physicians and Surgeons of Canada, through a Royal College Lectureship. This work was supported in part by the National Health Research Development Program, through a National Health Scholar Award to Dr. Rockwood. The Consortium of Canadian Centres for Clinical Cognitive Research was formed in 1992 by a group of investigators interested in collaborative work on dementia. It is chaired by Dr. Serge Gauthier at McGill University. Membership is open to any Canadian clinician or scientist wishing to join; a letter to that effect, with accompanying curriculum vitae, should be sent to the Secretary of the C5R, Dr. William Pryse-Phillips, at the Division of Neurology, Memorial University of Newfoundland, St. John's, Newfoundland A IC 3V6.

This paper is dedicated to the memory of our late colleague, Dr. Irma Parhad, whose insight and clear thinking have been of fundamental importance to the establishment of the C5R.

\section{REFERENCES}

1. Hay JW, Ernst RL. The economic costs of Alzheimer's disease. Am J Public Health 1987; 77: 1169-1175.

2. Erkinjuntti T, Hachinski V. Rethinking vascular dementia. Cerebrovasc Dis 1993; 3: 3-23.

3. Hachinski V. Preventable senility: a call for action against the vascular dementias. Lancet 1992; 340: 645-648.

4. Jorm AF. The Epidemiology of Alzheimer's Disease and Related Disorders. London: Chapman and Hall, 1990.

5. Rocca WA, Hofman A, Brayne C, et al. The prevalence of vascular dementia in Europe: facts and fragments from 1980-1990 studies. Ann Neurol 1990; 30: 817-824.

6. Brust JCM. Vascular dementia is overdiagnosed. Arch Neurol 1988; 45: 799-801

7. O'Brien MD. Vascular dementia is underdiagnosed. Arch Neurol 1988; 45: 797-798.

8. Erkinjuntti T, Haltia, Palo J, Sulkava R, Paetau A. Accuracy of the clinical diagnosis of vascular dementia: a prospective clinical and post-mortem neuropathological study. J Neurol Neurosurg Psychiatry 1988; 51: 1037-1044.

9. Phillips S, Whisnant JP. Hypertension and the brain. Arch Intern Med 1992; 152: 938-945.

10. Tatemichi TK. How acute brain failure becomes chronic: a view of the mechanisms of dementia related to stroke. Neurology 1990; 40: $1652-1659$.

11. Chui HC, Victoroff JI, Margolin D, et al. Criteria for the diagnosis of ischemic vascular dementia proposed by the State of California Alzheimer's Disease Diagnostic and Treatment Centers. Neurology 1992; 42: 473-480.

12. Roman GC, Tatemichi TK, Erkinjuntti T, et al. Vascular dementia: diagnostic criteria for research studies. Report of the NINDSAIREN International Workshop. Neurology 1993; 43: 250-260.

13. Drachman DA. New criteria for the diagnosis of vascular dementia: do we know enough yet? Neurology 1993; 43: 243-245.

14. Canadian Study of Health and Aging. The prevalence of dementia in Canada. Can Med Assoc J 1994; 150: 899-913.

15. Hachinski $\mathrm{V}$. The decline and resurgence of vascular dementia. Can Med Assoc J 1990; 142: 107-111.

16. Brust JCM. Vascular dementia reconsidered. Cerebrovasc Dis 1993; 3: 26.

17. Eastwood MR, Kennedy JF. Geriatric Psychiatry Curr Opinion Psychiatry 1993: 6; 557-561.

18. Jorm AF. A comparison of the ratio of Alzheimer's disease to vascular dementia in various countries. Eur Arch Psychiatry Clin Neurosci 1991; 240: 218-222.

19. Tatemichi TK, Desmond DW, Mayeux R, et al. Dementia after stroke: baseline frequency, risks and clinical features in a hospitalized cohort. Neurology 1992; 42: 1185-1193.

20. Marshall J. Vascular dementias. In: Whitehouse PJ, ed. Dementia Philadelphia: FA Davis, 1993.

21. Reaven, GM. Role of insulin resistance in human disease (syndrome X). Ann Rev Med 1993; 44: 121-131.
22. Rimmer JM, Gennari FJ. Atherosclerotic renovascular disease and progressive renal failure. Ann Intern Med 1993; 118: 712-719.

23. Brun A, Englund E. A white matter disorder in dementia of the Alzheimer type: a pathoanatomical study. Ann Neurol 1986; 19: 253-262.

24. Olszewski J. Subcortical arteriosclerotic encephalopathy: review of the literature of the so-called Binswanger's disease, and presentation of two cases. World Neurol 1962; 3: 359-375.

25. Gray F, Dubas F, Roullet E, Escourolle R. Leukoencephalopathy in diffuse hemorrhagic cerebral amyloid angiopathy. Ann Neurol 1986; 18: 54-59.

26. Vinters HV, Mah VH. Vascular diseases. In: Duckett S, ed. The Pathology of the Aging Human Nervous System Philadelphia: Lea \& Febiger, 1991 .

27. Hachinski VC, Iliff LD, Zilhka E, et al. Cerebral blood flow in dementia. Arch Neurol 1975; 32: 632-637.

28. Rosen WG, Terry RD, Fould PA, Katzman R, Peck A. Pathological verification of ischemic score in differentiation of dementias. Ann Neurol 1980; 7: 486-488.

29. World Health Organization. Manual of the International Statistical Classification of Diseases, Injuries and Causes of Death. 9th Revision. Geneva: World Health Organization, 1976.

30. World Health Organization. Manual of the International Statistical Classification of Diseases, Injuries and Causes of Death. 10th Revision. Geneva: World Health Organization, 1989. (Typescript document MNH/MEP/87.1, 25-31).

31. American Psychiatric Association. Diagnostic and Statistical Manual, 3rd ed. Washington: American Psychiatric Association, 1980.

32. American Psychiatric Association. Diagnostic and Statistical Manual, 3rd ed, Revised. Washington: American Psychiatric Association, 1987.

33. Roth M, Huppert FA, Tym E, Mountjoy CQ. (eds) CAMDEX: The Cambridge Examination for Mental Disorders of the Elderly Cambridge: Cambridge University Press, 1988.

34. Erkinjuntti T, Sulkava R. Diagnosis of multi-infarct dementia. Alzheimer Dis Assoc Dis 1991; 5: 112-121.

35. Erkinjuntti T, Laaksonen R, Sulkava R, Syrjalainen R, Palo J. Neuropsychological differentiation between normal aging, Alzheimer's disease and vascular dementia. Acta Neurol Scand 1986; 74: 393-403

36. Roman GC. Lacunar dementia. In: Senile Dementia of the Alzheimer Type. Alan R. Liss, 1985; 131-151.

37. Ishii $\mathrm{N}$, Nishihara $\mathrm{Y}$, Imamura $\mathrm{T}$. Why do frontal lobe symptoms predominate in vascular dementia with lacunes? Neurology 1986; 36: 340-345.

38. Wolfe N, Linn R, Babikian VL, Knoefel JE, Albert ML. Frontal systems impairment following multiple lacunar infarcts. Arch Neurol 1990; 47: 129-132.

39. Hougaku H, Matsumoto M, Kitagawa K, et al. Silent cerebral infarction as a form of hypertensive target organ damage in the brain. Hypertension 1992; 20: 816-820.

40. Kinkel WR, Jacobs L, Polachini I, Bates V, Heffner RR Jr. Subcortical arteriosclerotic encephalopathy (Binswanger's disease): computed tomographic, nuclear magnetic resonance, and clinical correlations. Arch Neurol 1985; 42:951-959.

41. Steingart A, Hachinski VC, Lau C, et al. Cognitive and neurologic findings in subjects with diffuse white matter lucencies on computed tomographic scan (leuko-araiosis). Arch Neurol 1987; 44: 32-35.

42. Kertesz A, Polk M, Carr T. Cognition and white matter changes on magnetic resonance imaging in dementia. Arch Neurol 1990; 47 387-391.

43. Rao SM, Mittenberg W, Bernardin L, Haughton V, Leo GJ. Neuropsychological test findings in subjects with leukoaraiosis. Arch Neurol 1989; 46: 40-44.

44. De Reuck J, Crevits L, De Coster W, Sieben G, vander Eecken H. Pathogenesis of Binswanger chronic progressive subcortical encephalopathy. Neurology 1980; 30: 920-928

45. Hunt AL, Orrison WW, Yeo RA, et al. Clinical significance of MRI white matter lesions in the elderly. Neurology 1989; 39: 1470-1474.

46. Tupler LA, Coffey E, Logue PE, Djang WT, Fagan SM Neuropsychological importance of subcortical white matter hyperintensity. Arch Neurol 1992; 49: 1248-1252. 
47. Brown J, Hesselink J, Rothrock J. MR and CT of lacunar infarcts. Am J Neuroradiol 1988; 9: 477-482.

48. Tatemichi TK, Foulkes MA, Mohr JP, et al. Dementia in stroke survivors in the Stroke Data Bank cohort. Prevalence, incidence, risk factors and computed tomographic findings. Stroke 1990; 21: 858-866.

49. Hachinski VC, Potter P, Merskey H. Leuko-araiosis. Arch Neurol 1987; 44: 21-23.

50. Kobari M, Meyer J, Ichijo M, Oravez W. Leuko-araiosis: correlation of MR and CT findings with blood flow, atrophy and cognition. Am J Neuroradiol 1990; 11: 273-281.

51. Janota I, Mirsen TR, Hachinski VC, Lee DH, Merskey H. Neuropathologic correlates of leuko-araiosis. Arch Neurol 1989; 46: 1124-1128.

52. Leifer D, Buonanno FS, Richardson EP Jr. Clinicopathologic correlations of cranial magnetic resonance imaging of periventricular white matter. Neurology 1990; 40: 911-918.

53. Heinz EK, Drayer BP, Haenngeli CA, et al. Computed tomography in white matter disease. Radiology 1979; 130: 371-378.
54. Lane B, Carroll BA, Pedley TA. Computerized cranial tomography in cerebral disease of white matter. Neurology 1978; 28: 534-544.

55. Inzitari D, Diaz F, Fox A, et al. Vascular risk factors and leukoaraiosis. Arch Neurol 1987; 44: 42-47.

56. George AJ, De Leon MJ, Gentes $\mathrm{Cl}$, et al. Leukoencephalopathy in normal and pathologic aging: 1. CT of brain lucencies. Am J Neuroradiol 1986; 7: 561-566.

57. Kase CS, Wolf PA, Chodosh EH, et al. Prevalence of silent stroke in patients presenting with initial stroke: The Framingham Study. Stroke 1989; 20: 850-852.

58. Chodosh EH, Foulkes MA, Kase CS, et al. Silent stroke in the NINCDS Stroke Data Bank. Neurology 1988; 38: 1674-1679.

59. Skoog I, Nilsson L, Palmertz B, Andreasson L, Svanborg A. A population-based study of dementia in 85-year-olds. N Engl J Med 1993; 328: 153-158.

60. Hachinski, VC, Bowler JV. Vascular dementia: diagnostic criteria for research studies. Neurology 1993; 43: 2159-2160. 